\title{
Botrytis cinerea, AGENTE CAUSAL DE MUERTE DE RETOÑOS DE Vaccinium corymbosum L. CV. BILOXI EN OAXACA, MÉXICO
}

\author{
Botrytis cinerea, THE CAUSAL AGENT OF TWIG DIEBACK OF \\ Vaccinium corymbosum L. CV. BILOXI IN OAXACA, MEXICO
}

\author{
Laura B. Montiel-Frausto y Alfonso Vásquez-López*
}

\begin{abstract}
Instituto Politécnico Nacional, Centro Interdisciplinario de Investigación para el Desarrollo Integral Regional Unidad Oaxaca, Santa Cruz Xoxocotlán, Oaxaca, México.

*Autor de correspondencia (bremia43@gmail.com)
\end{abstract}

\section{RESUMEN}

La muerte de retoños es una enfermedad asociada a hongos fitopatógenos que causa pérdidas importantes en especies del género Vaccinium. Esta enfermedad se observó en el cultivo de arándano (V. corymbosum L.) cv. Biloxi durante el ciclo productivo 2018 en la Sierra Norte de Oaxaca, México. El objetivo del presente estudio fue identificar morfológica y molecularmente el agente causal de la muerte de retoños de plantas de arándano cv. Biloxi, así como describir los daños histológicos que induce el patógeno. A partir de muestras de retoños con síntomas de necrosis, sembradas en medio de cultivo papa-dextrosa-agar $2 \%$ se obtuvieron aislamientos fungosos. El agente causal de la enfermedad se determinó mediante los postulados de Koch. El patógeno indujo marchitez y necrosis en retoños después de 10 días de la inoculación. El hongo se identificó morfológica y molecularmente como Botrytis cinerea; así mismo, se realizaron cortes histológicos en retoños con síntomas empleando la técnica de inclusión en parafina y tinción diferencial safranina 0-verde rápido. En los cortes histológicos se observó degradación, lisis y desorganización celular de la cutícula y epidermis; al interior de las células se observaron cuerpos amorfos de color rojo que probablemente correspondieron a polifenoles. Este documento constituye el primer reporte de $B$. cinerea causando la muerte de retoños en $V$. corymbosum cv. Biloxi en Oaxaca, México. La caracterización morfológica y molecular de este patógeno contribuye al conocimiento del agente causal para la búsqueda de estrategias de control y manejo integrado.

Palabras clave: Botrytis cinerea, Vaccinium corymbosum, histopatología, muerte de retoños

\section{SUMMARY}

Twig dieback is a disease associated with plant pathogenic fungi that causes significant losses in species of the genus Vaccinium. This disease was observed in blueberry ( $V$. corymbosum L.) cv. Biloxi plantations during the 2018 productive cycle at Sierra Norte of Oaxaca, Mexico. The aim of this study was to identify morphologically and molecularly the causal agent of twig dieback of blueberry plants cv. Biloxi, as well as to describe the histological damages induced by the pathogen. Fungal isolates were obtained from samples of twigs with necrosis symptoms and cultured in potato-dextrose-agar $2 \%$ medium. The causal agent of the disease was determined using the Koch's postulates. The pathogen induced wilting and necrosis in twigs after 10 days of inoculation. The fungus was identified morphologically and molecularly as Botrytis cinerea; in addition, histological sections of symptomatic twigs were performed using the paraffin embedding technique and safranin 0 -fast green differential staining. In the histological sections degradation, lysis and cellular disorganization of cuticle and epidermis were observed; inside these, amorphous red bodies were observed, probably corresponding to polyphenols. There was no evidence of penetration structures of the pathogen. This document constitutes the first report of $B$. cinerea causing twig dieback in V. corymbosum cv. Biloxi in Oaxaca, Mexico. Morphological and molecular characterization of this pathogen contributes to the knowledge of the causative agent for the search of control strategies and integrated management.

Index words: Botrytis cinerea, Vaccinium corymbosum, histopathology, twig dieback.

\section{INTRODUCCIÓN}

El arándano (Vaccinium corymbosum L.) es un cultivo de alto valor socioeconómico a nivel mundial, su consumo se ha incrementado debido a sus propiedades nutricionales y medicinales (Smith et al., 2000). En México, la producción de arándano aumentó 800 \% en los últimos 10 años, posicionando al país como cuarto productor a nivel mundial; los principales estados productores son Jalisco, Colima y Michoacán (SIAP, 20019). En San Pedro Nexicho, Sierra Norte del estado de Oaxaca, el cultivo de arándano se introdujo en 2015 (Zárate et al., 2017). En el ciclo productivo 2018 se observó la muerte de retoños en plantas del cv. Biloxi, cultivadas bajo cubierta o a cielo abierto; la incidencia estimada fue de 40 a $60 \%$. Esta incidencia posiblemente se relaciona con la existencia de plantas silvestres de zarzamora (Rubus spp.) con síntomas de muerte de retoños, tizón floral y moho gris de frutos asociados a Botrytis sp. En los cultivos de arándano de otras regiones de Oaxaca la incidencia de muerte de retoños fue de 2 a $5 \%$, por lo que no se considera de importancia económica.

La muerte del retoño del arándano puede ser inducida por Phomopsis vaccinium y P. columnaris (Farr et al., 2002), Lasiodiplodia theobromae (Wang et al., 2016), 
Neopestalotiopsis (Lee et al., 2019) o Colletotrichum acutatum (Yoshida et al., 2007). Los retoños sufren marchitez, necrosis y muerte (Zhao et al., 2019). En Oaxaca no se conoce con precisión al agente causal de la muerte del retoño del arándano. El objetivo del presente estudio fue identificar morfológica y molecularmente el agente causal de la muerte de retoños de plantas de arándano cv. Biloxi, así como describir los daños histológicos que induce el fitopatógeno. El conocimiento del agente causal permitirá establecer estrategias efectivas de control y contribuirá al mejoramiento de la producción de arándano en la Sierra Norte del estado de Oaxaca, México.

\section{MATERIALES Y MÉTODOS}

En un huerto comercial de arándano cv. Biloxi; ubicado en San Pedro Nexicho (17 $05^{\prime} \mathrm{N}, 96^{\circ} 31^{\prime} \mathrm{O}, 2120$ msnm), municipio de Santa Catarina Ixtepeji, Oaxaca; en el ciclo productivo 2018, se muestrearon 20 retoños con síntomas de marchitez y necrosis descendente. Por cada retoño se obtuvieron cinco secciones de tejido de $5 \mathrm{~mm}^{2}$. Las muestras se desinfestaron por inmersión en $\mathrm{NaClO} 2$ \% durante 3 min, se enjuagaron con agua destilada estéril y se secaron sobre toallas de papel estéril. El tejido se sembró en medio de cultivo agar-dextrosa-papa (PDA) $2 \%$, Bioxon ${ }^{\circledR}$ y se incubó durante $10 \mathrm{~d}$ a $25^{\circ} \mathrm{C}$ y fotoperiodo de $16 \mathrm{~h}$ luz y $8 \mathrm{~h}$ de oscuridad. Los hongos que crecieron a partir de tejido enfermo se aislaron y se purificaron por la técnica de cultivo monoconidial. Las pruebas de patogenicidad se realizaron con una colonia de $10 \mathrm{~d}$ de crecimiento de donde se preparó una suspensión de conidios $\left(1 \times 10^{4}\right.$ conidios $\mathrm{mL}^{-1}$ ) y el conteo de conidios se realizó con la cámara de Neubauer (Blaubrand ${ }^{\circledR}$, Wertheim, Alemania). En San Pedro Nexicho se adquirieron cinco plantas asintomáticas de arándano cv. Biloxi de 1.5 años de edad, sembradas en contenedores plásticos de $30 \mathrm{~L}$ con una mezcla de suelo agrícola (30 \%) y corteza de pino (70 \%); se llevaron al laboratorio de Fitopatología del CIIDIR Unidad Oaxaca del Instituto Politécnico Nacional; se seleccionaron 20 ramas asintomáticas con retoño; las ramas se lavaron con agua destilada estéril y etanol 70 \% y se inocularon por aspersión con $5 \mathrm{~mL}$ de la suspensión conidial. Se utilizó agua destilada estéril como control. El material vegetal inoculado se mantuvo en cámara húmeda por $48 \mathrm{~h}$ con fotoperiodo de 16 h luz y 8 h de oscuridad. La cámara húmeda consistió de una bolsa de polipapel transparente y estéril que cubrió la rama inoculada. De los retoños que se enfermaron se aisló nuevamente el patógeno y se comparó morfológica y molecularmente con el hongo originalmente inoculado.

La extracción de ADN se realizó con bromuro de cetil trimetilamonio (CTAB) 2 \% (Doyle y Doyle, 1990) adicionado con acetato de amonio 3 M. La amplificación de la región del espaciadortranscritointerno(ITS)serealizóconlosiniciadores universales ITS5 (5'-GGAAGTAAAAGTCGTAACAAGG-3') e ITS4 (5'-TCCTCCGCTTATTGATATGC-3') (White et al., 1990). La reacción de amplificación consistió de un volumen final de $25 \mu \mathrm{L}$ [3 $\mu \mathrm{L}$ de ADN genómico (50 ng), $12.5 \mu \mathrm{L}$ de GoTaq ${ }^{\oplus}$ Green Master Mix (Promega, Madison, Wisconsin, EUA), 1 $\mu \mathrm{L}$ de cada iniciador y $8.5 \mu \mathrm{L}$ de agua libre de nucleasas]. El protocolo de termociclado incluyó desnaturalización inicial de 2 min a $95^{\circ} \mathrm{C}$; 35 ciclos de desnaturalización de 1 min a $95^{\circ} \mathrm{C}, 30 \mathrm{~s}$ a $58^{\circ} \mathrm{C}$ y una extensión de $20 \mathrm{~s}$ a 72 ${ }^{\circ} \mathrm{C}$, y extensión final a $72{ }^{\circ} \mathrm{C}$ durante 5 min. Los productos amplificados se visualizaron mediante electroforesis en gel de agarosa $1 \%$ teñido con bromuro de etidio. El producto de PCR fue purificado y secuenciado en Macrogen (Seoul, República de Corea del Sur). Las secuencias de ADN fueron editadas y ensambladas con el programa BioEdit v7.0.5 (Hall, 1999). Las secuencias consenso se compararon con las secuencias depositadas en el GenBank del National Center for Biotechnology Information (NCBI).

El estudio histopatológico se realizó siguiendo la técnica de inclusión en parafina (Johansen, 1940) y tinción diferencial con safranina $\mathrm{O}$ ácida y verde rápido (Curtis et al., 1986). Veinte muestras de retoños sintomáticos se fijaron en solución FAA (50 \% de etanol absoluto, $5 \%$ de ácido acético glacial, $10 \%$ de formaldehído y $35 \%$ de agua destilada) durante $48 \mathrm{~h}$ a $4{ }^{\circ} \mathrm{C}$. La técnica de inclusión en parafina incluyó tres lavados de las muestras con alcohol etílico al 50 \%, cada lavado duró 15 min; la deshidratación se hizo con alcohol etílico en concentraciones ascendentes de 50, 70, 96 y $100 \%$; las muestras estuvieron inmersas durante 3 h en cada alcohol; la clarificación se efectuó con alcohol etílico $100 \%$ y con xileno, cada paso duró 2 h. La infiltración se hizo introduciendo las muestras en parafina histológica líquida $\mathrm{Hyce}^{\circledR}$ a $70{ }^{\circ} \mathrm{C}$, el proceso se realizó dos veces, cada uno duró $3 \mathrm{~h}$; la inclusión de las muestras en parafina se realizó en cubos de papel de $3 \mathrm{~cm}^{3}$; dentro de los cubos se colocaron las muestras y se cubrieron con parafina histológica líquida Hycel ${ }^{\circledR}$ a $70{ }^{\circ} \mathrm{C}$; la parafina se dejó solidificar a $4^{\circ} \mathrm{C}$.

El tejido se cortó en un micrótomo (Bright Instruments Co. Ltd., Luton, Bedfordshire, Inglaterra) a $10 \mu \mathrm{m}$ de espesor, los cortes se colocaron en baño de flotación (agua a $70{ }^{\circ} \mathrm{C}+3 \mathrm{~g}$ de grenetina $\mathrm{L}^{-1}$ ) durante 1 min y se montaron en portaobjetos; posteriormente, los portaobjetos se colocaron en una estufa a $45{ }^{\circ} \mathrm{C}$ durante 20 min para eliminar el exceso de parafina; las muestras se lavaron tres veces consecutivas con xileno; cada lavado duró 3 min; se hidrataron con alcohol en concentraciones descendentes al 100, 96, 70 y $50 \%$ durante 3 min por concentración. La técnica de tinción diferencial incluyó la tinción de las muestras con safranina $\mathrm{O}$ ácida, donde estuvieron 
inmersas durante 4 h; la deshidratación se realizó con alcohol en concentraciones gradualmente ascendentes al 50,70 y 96 \% durante 3 min por concentración; la segunda tinción se realizó con verde rápido durante 20 s; luego, se deshidrataron con alcohol al 96 y $100 \%$ durante 3 min por concentración y se lavaron con xileno tres veces. Sobre la muestra se agregó resina sintética y se colocó un cubreobjetos. Las preparaciones se observaron con un microscopio de luz (Carl Zeiss Primo Star ${ }^{\circledR}$, White Plains, New York, EUA).

\section{RESULTADOS Y DISCUSIÓN}

Del tejido sintomático obtenido en campo (Figuras 1A y 1B) se aisló consistentemente (97\%) a Botrytis sp. En las pruebas de patogenicidad, el aislado inoculado indujo inicialmente pequeñas lesiones necróticas que después aumentaron de diámetro hasta coalescer con otras; las hojas sufrieron marchitez y necrosis; el daño se extendió al tejido de ramas adyacentes. Estos síntomas se observaron a los 10 días después de la inoculación. En el tratamiento testigo no se observaron síntomas. Los síntomas de muerte de retoños en especies de Vaccinium se ha atribuido a Phomopsis vaccinium y P. columnaris (Farr et al., 2002), Lasiodiplodia theobromae (Wang et al., 2016), Neopestalotiopsis (Lee et al., 2019) y a Colletotrichum acutatum (Yoshida et al., 2007).
El micelio de Botrytis fue de aspecto algodonoso; en los primeros $3 \mathrm{~d}$ el cultivo fue de color blanco y después se tornó café oscuro; a los 10 d se observó abundante producción de conidios. Después de 30 d la cepa produjo en promedio 45 esclerocios por caja de Petri de $100 \times 15$ $\mathrm{mm}$; los esclerocios fueron de forma irregular, oscuros y compactos, de 1.5 a $2.5 \mathrm{~mm}$ (Figura 1C). El hongo aislado produjo hifas septadas, conidióforos septados con pared lisa y en los ápices conidios en racimos (Figura 1D); los conidios fueron unicelulares, hialinos y elipsoidales de 7.8 a $12.0 \times 9.6$ a $17.7 \mu \mathrm{m}$ largo-ancho (Figura 1E). Con base en las características morfológicas, el aislado coincidió con las características de $B$. cinerea descritas por Mansouripour y Holmes (2002). La secuencia de ADN obtuvo una similitud del $100 \%$ con la secuencia MN589850 (569 pb) depositada en el NCBI, correspondiente a la especie B. cinerea.

En cortes histológicos de tejido de retoños necróticos (rama tierna) se observó degradación, lisis y desorganización celular de la cutícula y epidermis (Figura $1 \mathrm{~F}$ ); dentro de ellas, se observaron cuerpos amorfos de color rojo que probablemente correspondieron a polifenoles (Figura 1G), los cuales están estrechamente relacionados con la defensa de la planta contra patógenos necrotróficos (AbuQamar et al., 2017). No se observaron estructuras de penetración del hongo, lo cual sugiere posibles daños por degradación enzimática de pectinasas, celulasas

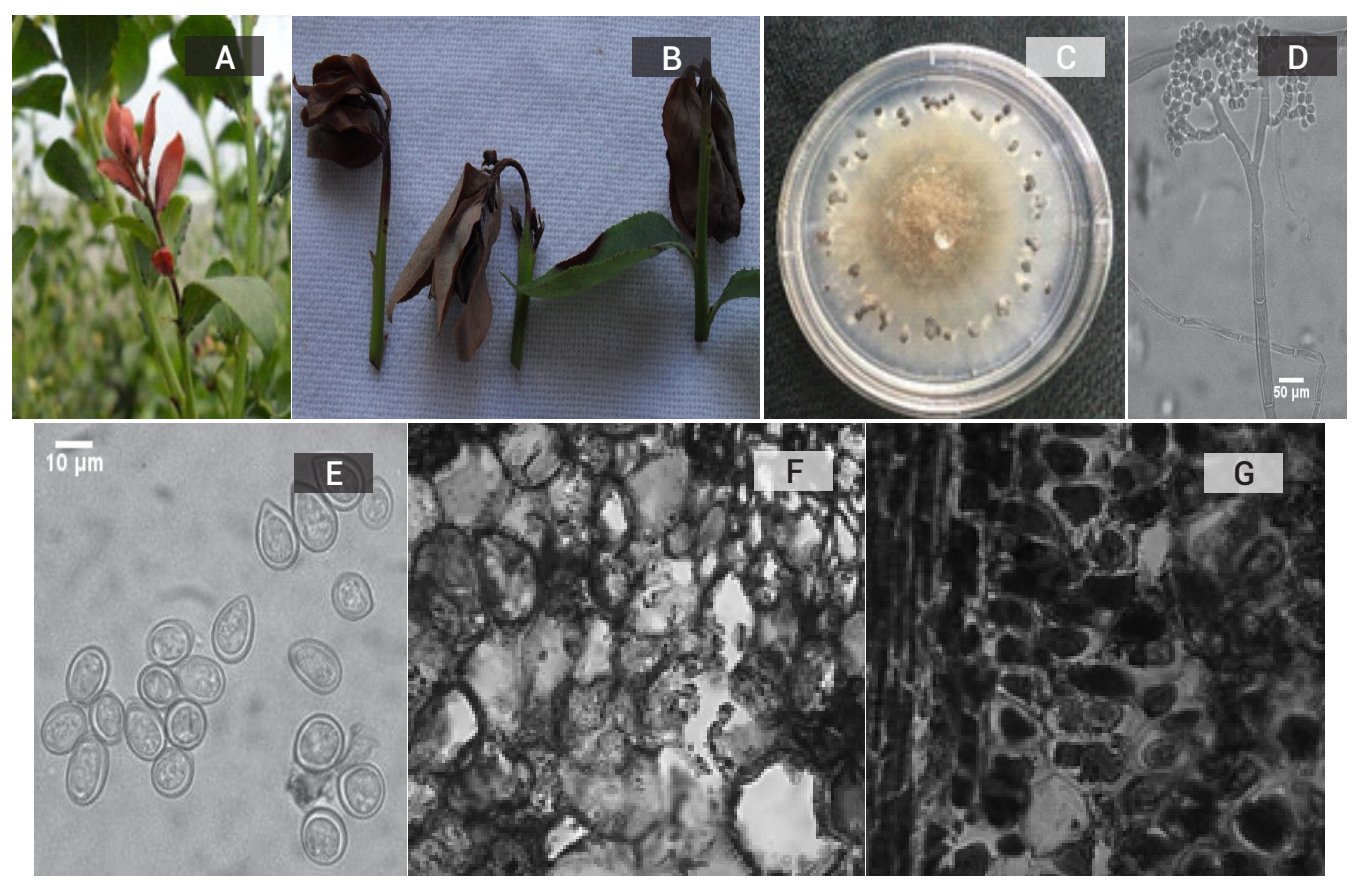

Figura 1. Muerte de retoño en Vaccinium corymbosum cv. Biloxi. A y B) retoños con necrosis descendente, C) Botrytis cinerea en medio de cultivo PDA con formación de esclerocios después de 30 días de incubación, D) conidióforo y conidios en racimos, E) conidios unicelulares, hialinos y elipsoidales, F) corte histológico longitudinal de una ramita de retoño de arándano, se observa degradación, lisis y desorganización celular de la epidermis, G) células de la epidermis conteniendo cuerpos amorfos que posiblemente corresponden a polifenoles. 
y hemicelulasas. Botrytis cinerea se caracteriza por la producción de compuestos fitotóxicos de tipo lactonas y sesquiterpenos durante la infección, por lo que es capaz de causar muerte celular antes de invadir a las células del hospedante por el hábito nutricional necrotrófico del patógeno (AbuQamar et al., 2017; Dinh et al., 2011).

Se identificó morfológica y molecularmente a Botrytis cinerea como agente causal de la muerte de retoños de arándano cv. Biloxi. El hongo causó desorganización, lisis y muerte de las células de la cutícula y epidermis de los retoños con síntomas de necrosis. La identificación precisa del hongo fitopatógeno permitirá plantear estrategias de manejo y control integrado para disminuir las pérdidas por B. cinerea en el cultivo de arándano cv. Biloxi en la Sierra Norte del estado de Oaxaca.

\section{BIBLIOGRAFÍA}

AbuQamar S., K. Moustafa and L. S. Tran (2017) Mechanisms and strategies of plant defense against Botrytis cinerea. Critical Reviews in Biotechnology 37:262-274, https://doi.org/10.1080 /07388551.2016.1271767

Curtis P. J. (1986) Microtecnia Vegetal. Trillas. México, D. F. 106 p.

Dinh S. Q., D. C. Joyce, D. E. Irving and A. H. Wearing (2011) Histology of waxflower (Chamelaucium spp.) flower infection by Botrytis cinerea. Plant Pathology 60:278-287, https://doi.org/10.1111/ j.1365-3059.2010.02347.x

Doyle J. J. and J. L. Doyle (1990) Isolation of plant DNA from fresh tissue. Focus 12:13-15.

Farr D. F., L. A. Castlebury, A. Y. Rossman and M. L. Putnam (2002) A new species of Phomopsis causing twig dieback of Vaccinium vitis-idaea (lingonberry). Mycological Research 106:745-752, https://doi.org/10.1017/S095375620200583X
Hall T. A. (1999) BioEdit: a user-friendly biological sequence alignment editor and analysis program for Windows 95/98/NT. Nucleic Acids Symposium Series 41:95-98, https://10.14601/ Phytopathol_Mediterr-14998u1.29

Johansen D. A. (1940) Plant Microtechnique. McGraw-Hill Book Company. New York, USA. 503 p.

Lee Y., G. H. Kim, Y. Kim, S. Y. Park and Y. J. Koh (2006) First report of twig dieback caused by Neopestalotiopsis clavispora on blueberry in Korea. Plant Disease 103:1022, https://doi.org/10.1094/ PDIS-10-18-1734-PDN

Mansouripour S. and G. J. Holmes (2020) First report of Botrytis cinerea causing leaf spot on strawberry in California. Plant Disease 104:1866, https://doi.org/10.1094/PDIS-06-19-1287-PDN

SIAP, Servicio de Información Agroalimentaria y Pesquera (2019) Anuario estadístico de la producción agrícola. Secretaría de Agricultura y Desarrollo Rural. Ciudad de México. https://nube.siap.gob. $\mathrm{mx}$ /cierreagricola/ (Noviembre 2020).

Smith M. A. L., K. A. Marley, D. Seigler, K. W. Singletary and B. Meline (2000) Bioactive properties of wild blueberry fruits. Journal of Food Science 65:352-356, https://doi.org/10.1111/j.1365-2621.2000 tb16006.x

Wang J. N., H. H. Zhao, Y. Y. Yu, X. D. Li, C. Liang and B. D. Li (2016) The pathogen causing Lasiodiplodia twig blight of blueberry Mycosystema 35:657-665, https://doi.org/10.13346/j. mycosystema. 150165

White T. J., T. Bruns, S. Lee and J. Taylor (1990) Amplification and direct sequencing of fungal ribosomal RNA genes for phylogenetics. In: PCR Protocols: A Guide to Methods and Applications M. A. Innis, D. H. Gelfand, J. J. Sninsky and T. J. White (eds.) Academic Press. New York, USA. pp:315-322

Yoshida S., T. Tsukiboshi, H. Shinohara, M. Koitabashi and S. Tsushima (2007) Occurrence and development of Colletotrichum acutatum on symptomless blueberry bushes. Plant Pathology 56:871-877, https://doi.org/10.1111/j.1365-3059.2007.01645.x

Zárate N. B., A. Yescas A. y V. J. Morales D. (2017) Manejo agronómico del cultivo de arándano (Vaccinium corymbosum L.) en la Sierra Norte de Oaxaca. Universidad y Ciencia 6:138-155.

Zhao L., Y. Wang, W. He and Y. Zhang (2019) Stem blight of blueberry caused by Lasiodiplodia vaccinii sp. nov. in China. Plant Disease 103:2041-2050. https://doi.org/10.1094/PDIS-01-19-0079-RE 